\title{
REVIEW ON SLOPE STABILITY ANALYSIS AND EVALUATION
}

\author{
Elias Kassahun Woldeselsassie \\ School of Resource and Environmental Engineering \\ Wuhan University of Technology \\ Wuhan, Hubei, China
}

\begin{abstract}
Rock slope stability assessment is basically used for designing and evaluating the slope stability of the rock and mean while this is used for safety of the mine site. Rock slope hazard assessment is an important part of risk analysis for open pit mines. The main parameters that can lead to

slope failures are the parameters traditionally used in geo-mechanical classifications, the slope geometrical parameters and external factors like rainfall and blasting. This paper presents for reviewing different methods of assessment technique and put out some referential idea through

the paper.
\end{abstract}

Key word: Probabilistic assessment, Quantitative hazard assessment, Slope stability, Multivariate statistics.

\section{INTRODUCTION}

The open-pit mining technique came into being when human beings began to use rock as the original tool about 450,000 years ago. The modern concept about open-pit mining was firstly proposed when the lowgrade porphyry opencast copper mine in Utah Bingham Canyon was operated in 1903. After that, the open-pit mining technique entered an era of mechanized and large-scale mining activity. Since the 1950s, the open-pit mining projects have been frequently

reported by virtue of its increasing production and intensification in association with improvement of labor productivity. Because of such characteristics as large scale, high effectiveness and high productivity, the open-pit mining technology is commonly used in the solid mineral exploitation, including building materials; about $80 \%$ solid mineral was exploited with the open-pit mining technique.
Chi Xiuwen, Dereje Demissie, Tamrat Mekonnen

School of Resource and Environmental Engineering Wuhan University of Technology

Wuhan, Hubei, China

\subsection{Rock Mass Classification Schemes:}

Various researchers have proposed different type of rock mass classification systems, which find numerous applications in various aspects of rock mechanics. Bieniawski (1974) introduced the rock mass rating (RMR). The RMR-system incorporates six parameters, whose values are added to obtain a total RMR rating to characterize a rock mass. After 1974, the classification has undergone several changes and it is important to state which version of the system is used Hoek-Brown (Hoek and Brown, 1988). The rock mass strength (RMS) classification (Stille et al. 1982) is a modification of the RMR-system. The sum of the parameters and the rating reduction with respect to joints set is the RMS-value for the rock mass. The Rock Quality Designation index (RQD) was developed by Deere (Deere et al. 1967) to provide a quantitative estimate of rock mass quality from drill core logs. This is also estimated through indirectly on the number of fractures and amount of softening or alteration in the rock mass as observed in the rock cores from a drill hole. The geological strength index (GSI) was introduced as a complement to their generalized rock failure criterion (Hoek et al. 1995) which are in turn, used when estimating the parameters "s", "a" and "mb" in the Hoek-Brown criterion, using empirical equations. The GSI system was introduced to overcome the deficiencies in RMR for very poorquality rock masses. The original GSI table has been subject to several minor revisions, as well as additions to classify; particularly weak and soil-like rock masses (Hoek et al. 2002).

\subsection{Slope Mass Rating:}

Slope Mass Rating is a modified RMR system for slope, developed by Romana (1985). SMR is a useful rating tool for evaluation of slope instability risk based on slope face relation with geological discontinuities. 


$$
\mathrm{SMR}=\mathrm{RMR}-(\mathrm{F} 1 \cdot \mathrm{F} 2 \cdot \mathrm{F} 3)+\mathrm{F} 4 .
$$

The adjustment rating of joints is the product of three factors: F1 depends upon the parallelism between joints and slope face strike. It ranges from 1.0 to 0.15 . The values are empirically established by the formula:

$$
\mathrm{F} 1=(1-\operatorname{Sin} \mathrm{A})^{2}
$$

Where $\mathrm{A}=$ Angle between the strike slope face and joints. F2 refers to the joint dip angle in the planar mode of failure. Its values range from 1.00 to 0.15 . The empirically established formula is:

$$
\mathrm{F} 2=\tan ^{2} \mathrm{Bj}
$$

Where $\mathrm{Bj}=$ joint dip angle. $\mathrm{F} 3$ indicates to the relationship between slope face and joint dip. In planar mode of failure, F3 refers to the probability of joints day lighting on the slope face. Condition is favorable when slope face and joints are parallel and unfavorable when slope dips 10 degree more than joints. F4 - Adjustment factor for method of excavation has been fixed empirically and are follows Natural slope $=+15$, Presplitting $=+10$, Smooth blasting $=+8$, Normal blasting $=0$, Deficient blasting $=-8$ and Mechanical excavation $=0$.

According to the SMR values, Romana (1985) defined

\begin{tabular}{|c|c|c|c|c|c|}
\hline Class & $\mathbf{V}$ & IV & III & II & I \\
\hline SMR Values & $0-20$ & $21-40$ & $41-60$ & $61-80$ & $81-100$ \\
\hline $\begin{array}{l}\text { Rock mass } \\
\text { description }\end{array}$ & Very bad & $\mathrm{Bad}$ & Normal & Good & Very good \\
\hline Stability & $\begin{array}{l}\text { Completely } \\
\text { unstable }\end{array}$ & Unstable & Partial stable & Stable & $\begin{array}{l}\text { Completely } \\
\text { stable }\end{array}$ \\
\hline Failures & 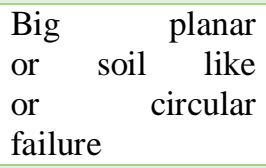 & $\begin{array}{l}\begin{array}{l}\text { Planar or big } \\
\text { wedges }\end{array}\end{array}$ & $\begin{array}{l}\text { Planar along } \\
\text { Some joints and } \\
\text { Many wedge } \\
\text { failure }\end{array}$ & $\begin{array}{l}\text { Some } \\
\text { block } \\
\text { failure }\end{array}$ & No failure \\
\hline $\begin{array}{l}\text { Probability } \\
\text { of Failure }\end{array}$ & 0.9 & 0.6 & 0.4 & 0.2 & 0 \\
\hline
\end{tabular}
five stability classes. They are described in Table 1

Table 1: Stability Classes as per SMR Values (Romana, 1985)

\subsection{Slope Monitoring Systems}

Relative displacement measurements are the most common type of monitoring, complemented by monitoring of groundwater. The most important purpose of a slope monitoring program is to:

1. Maintain safe operational practices;

2. Provide advance notice of instability; and

3. Provide additional geotechnical information regarding slope behavior (Sjöberg, 1996).
The following is a list of the most common monitoring systems currently in use and is not intended to be an all-inclusive list of monitoring equipment. Readers interested in a more comprehensive list are referred to Szwedzicki, 1993.

\subsubsection{Surface Measurements}

\subsubsection{Survey Network:}


A survey network consists of target prisms placed on and around areas of anticipated instability on the slopes, and one or more non-moving control points for survey stations. The angles and distances from the survey station to the prisms are measured on a regular basis to establish a history of movement on the slope. It is extremely important to place the permanent control points for the survey stations on stable ground. The surveys can be done manually by a survey crew or can be automated.

\subsubsection{Tension Crack Mapping:}

The formation of cracks at the top of a slope is an obvious sign of instability. Measuring and monitoring the changes in crack width and direction of crack propagation is required to establish the extent of the unstable area. Existing cracks should be painted or flagged so that new cracks can be easily identified on subsequent inspections. Measurements of tension cracks may be as simple as driving two stakes on either side of the crack and using a survey tape or rod to measure

the separations. Another common method for monitoring movement across tension cracks is with a portable wire-line extensometer.

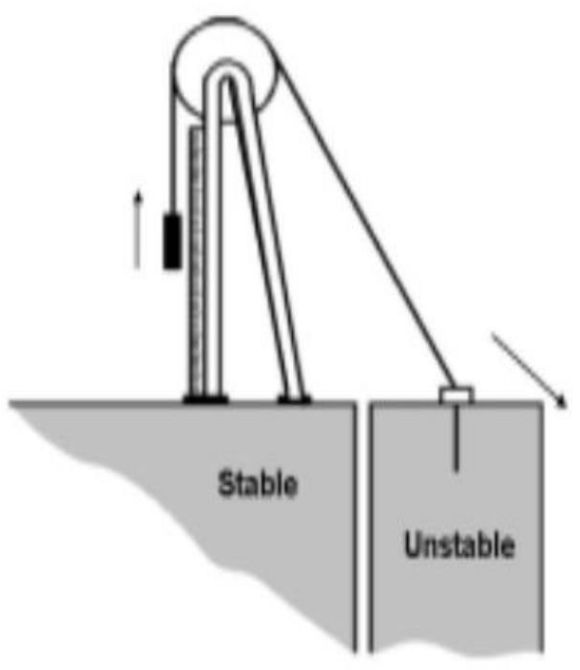

Figure 1 Portable wire-line extensometer for monitoring a tension crack.

The most common setup is comprised of a wire anchored in the unstable portion of the ground, with the monitor and pulley station located on a stable portion of the ground behind the last tension crack. The wire runs over the top of a pulley and is tensioned by a weight suspended from the other end. As the unstable portion of the ground moves away from the pulley stand, the weight will move and the displacements can be recorded either electronically or manually. Long lengths of wire can lead to errors due to sag or to thermal expansion, so readjustments and corrections are often necessary. The length of the extensometer wire should be limited to approximately $60 \mathrm{~m}(197 \mathrm{ft})$ to keep the errors due to line sag at a minimum (Call and Savely, 1990).

\subsubsection{Subsurface Measurements}

\subsubsection{Inclinometers:}

An inclinometer consists of a casing that is placed in the ground through the area of

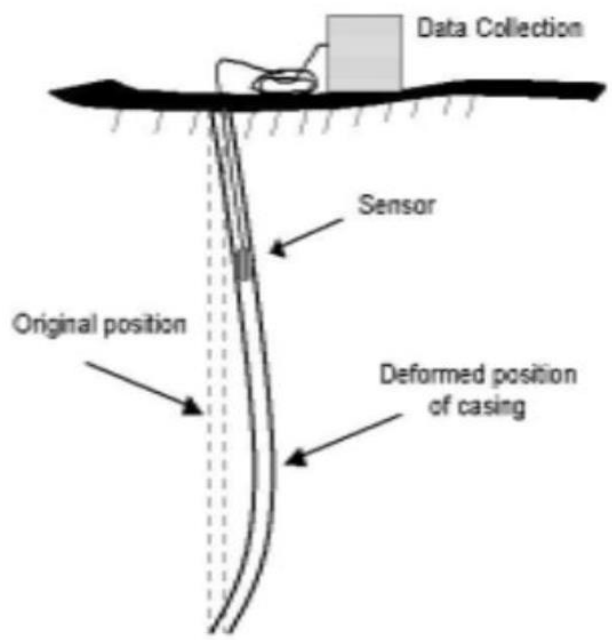

Figure 2 Cross-sectional schematic of typical traverse-probe inclinometer system.

expected movements. The end of the casing is assumed to be fixed so that the lateral profile of displacement can be calculated. The casing has grooves cut on the sides that serve as tracks for the sensing unit.

The deflection of the casing, and hence the surrounding rock mass, are measured by determining the inclination of the sensing unit at various points along the length of the installations. The information collected from the inclinometers is important to slope stability studies for the following reasons (Kliche, 1999):

- To locate shear zone(s);

- To determine whether the shear along the zone(s) is planar or rotational;

- To measure the movement along the shear zone(s) and determine whether the movement is constant, accelerating, or decelerating. 


\subsubsection{Time Domain Reflectometry (TDR):}

Time Domain Reflectometry is a technique in which electronic pulses are sent down a length of a coaxial cable. When deformation or a break in the cable is encountered, a signal is reflected giving information on the subsurface rock mass deformation. While inclinometers are more common for monitoring subsurface displacements, TDR cables are gaining popularity and have several advantages over traditional inclinometers (Kane, 1998):

- Lower cost of installation.

- Deeper whole depths possible.

- Rapid and remote monitoring possible.

- Immediate deformation determinations.

- Complex installations possible

Recent advances have also been made in the use of TDR for monitoring ground water levels and piezometric pressures (Dowding, et al. 1996). A summary of applications of TDR in the mining industry is provided by O'Connor and Wade (1994).

\subsubsection{Borehole Extensometers:}

An extensometer consists of tensioned rods anchored at different points in a borehole that the figure represents below. Changes in the distance between the anchor and the rod head provide the displacement information for the rock mass.

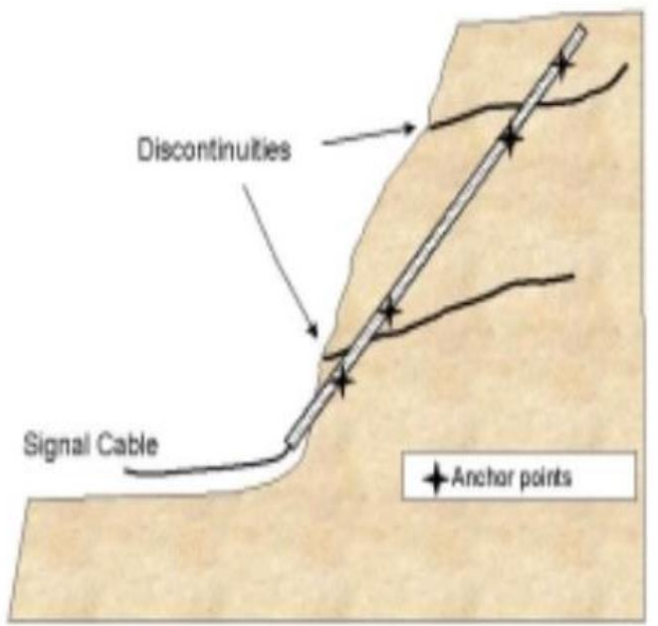

Figure 3 Multi-point borehole extensometer

\section{ALTERNATE ASSESSMENT OF SLOPE STABILITY}

\subsection{Probabilistic assessment of rock slopes stability using the response surface approach.}

Discontinuities are a considerable source of uncertainty and variability in engineering design of rock slopes. Rock slopes are often found in complex and rugged terrains such as mountainous areas, where strength and geometric properties of the discontinuities are subjected to change within a rock slope.

Due to these variations in both the strength and geometric properties of discontinuities in rock slopes, the field measurements of their geometric and mechanical characteristic are subject to variation in terms of accuracy and in the error ratio. As a result, rock slope design studies involve a lot of uncertainties. The origin of these uncertainties in the geotechnical data and analysis can be from several sources, for instance, the methods used in the data acquisition, the analysis techniques, the judgment that depends on the experience of the engineer, the methodology used in the study and other sources, all of which could influence the output results.

In the past few decades, many studies have considered the effect of the inherent variability of geotechnical properties in rock masses onto the stability conditions of rock slopes. This type of studies relies on determining a range of stability factors (factor of safety) to describe the stability behavior of a rock slope by incorporating different combinations of controlling factors, such as cohesion and friction angle to be used as input parameters (independent variables), with numerical modeling, and then identifying the most influential factors that play a significant role on the output or factor of safety. This type of method is known as the probabilistic approach. It is more efficient than the deterministic approach, which is based on the analysis of the mean value of the input variables to derive a single value of the output or factor of safety.

Numerous probabilistic methods have been proposed in the field of geotechnical engineering specifically in slope stability studies. Most of these methods have been developed to address the influence of the inherent variability of strength properties for slope stability assessment in a realistic manner.

Some studies have also discussed the influence of geometric parameters, particularly, the characteristics of joint networks, which have been successfully 
incorporated in the stability assessment of rock slopes. In addition, the impact of different joint surface properties on the overall stability condition of rock slopes has been captured and analyzed.

Hammah et al, 2008. discussed the application of probabilistic approach with numerical modeling. Two probabilistic approaches have been adopted in the analysis, the point estimate method (PEM) and MonteCarlo technique, to evaluate the probability of failure of a rock slope. This analysis takes into considerations the influence of joint network on different stability conditions. The study concluded that the PEM gives good results for probability assessment with reasonable computational cost, but the method suffers from curse of dimensionality (increased number of variables). On the other hand, the Monte-Carlo method is a powerful tool and more flexible to incorporate a wide range of probability distributions without being affected by the curse of dimensionality.

Brideau et al. investigated the natural variability of the geometric parameters in joint surfaces such as persistence, spacing and orientation on the stability conditions of a rock slope. The authors used a 3D distinct element code for stability assessment. The results show that the joint surfaces, with unfavorable persistence (fully extended) and both fixed spacing and orientation values do not always show a conservative solution.

A response surface approach was also presented as an efficient tool to identify the likelihood of the instability behavior of a rock slope. This approach has been applied using the central composite design (CCD), which is one of the statistical design methods used to implement experiments to examine the effects of the main interactions of different levels of the independent variables on the resulting response (dependent variable). As a result, an equation for the response, i.e. factor of safety, is established as a function of the design variables (independent variables) of the response surface. The resulting mathematical model or the response equation is used to estimate the probability of the unsatisfactory performance in the rock slope. This technique is efficient because it can be used to generate a wide range of output values (dependent variables). i.e., factor of safety along with Monte-Carlo technique, with low computational effort. This is particularly useful when the input variables include geometric parameters, such as, the orientation of discontinuities, where the technique allows for the change of the inputs without the need to re-construct the model itself many times.
In general, the stability condition in the rock slopes with joint network is significantly controlled by rock structures. This kind of failure mechanism is known as structurally controlled failure. These rock structures are mainly represented by discontinuities, joints, bedding planes, faults, etc. The geometric aspects, such as dip and dip direction, and the strength properties, such as friction angle and cohesion of the discontinuous surfaces, are the critical parameters that play the important role in the instability of rock slopes on road construction projects.

The stability condition of an excavated rock slope in mountainous areas using the response surface methodology is assessed. The analysis of a rock slope model with a single joint set as a representative of the dominant joint is adopted. Three parameters, dip, dip direction and friction angle for the rock joint surface are considered probabilistically, the extent of the joint is assumed to be infinite (persistence $=1$ ), and the cohesion is assumed to be zero with no infilling materials. The study area is exposed to very highly intense seasonal rainstorms during certain time periods of the year and most of the rock failures occur in rain times. Thus, we evaluate the probability of unsatisfactory of performance for the rock slope in the case of dry condition and then consider the effect of pore water pressure. We analyze both conditions of the rock slopes and compare their stability behaviors to identify the critical situations. Consequently, the remedial measures and means of mitigations are suggested based on the estimate of the critical factor of safety calculated in different weather conditions in the study region. The Box-Behnken design (BBD) is selected as a response surface design to study the effect of the variability of the three independent variables on the resulting output variable i.e. factor of safety. The BBD is a three-level design used to establish an equation to predict the factor of safety in the form of a second order polynomial. This approach is appropriate for the case that involves three factors and usually gives accurate results like the CCD but with less computational time.

\subsection{Quantitative hazard assessment system (Has-Q) for open pit mine slopes}

Standards Australia defines hazard as a source of potential harm; and a potential occurrence or condition that could lead to injury, damage to the environment, delay or economic loss.

In open pit slopes, potential harm is directly related to the occurrence and the volume of material in the slope 
failure. Three scales of slope failures can occur in an open pit mine: bench failure, inter ramp failure and overall failure.

These three types of scale of slope failures are directly related to the volume of the slope failure and, therefore, related to the consequences of these failures. Once the volume of failures is related to the consequences of these failures, the levels of acceptance criteria in probabilistic stability analysis vary according to the severity of the failure. Swan et al. provide recommendations of acceptable levels of probability of failure in open pit slopes. The acceptance criterion of the probability of failure in open pit mines, proposed by the authors, is directly related to the consequences of the failures. The greater the failure consequences, the lower the level of tolerance accepted.

Bench failures have less serious consequences. In general, this type of failures has a minimum economic impact on production, mostly related to cleanup costs. Damage to equipment and injuries to personnel are unlikely provided that the failure does not occur when the slope is under construction. Swan and Sepulveda state that bench failures are inevitable and permissible provided the acceptable contained volumes of material on benches are unlikely to be exceeded. Nonetheless, benches located immediately above and below ramps and those in the final wall must have lower tolerances of failure compared to the other benches. Priest and Brown also suggest that the consequences of failures in individual benches, temporary slopes and benches that are not adjacent to haulage roads are not largely serious.

The consequences of inter-ramp failures are more significant than the bench failures. Injuries to personnel and damage to equipment are likely. The economic impact on production is also more significant as the production losses and cleanup costs are usually greater than the bench failures. Acceptance of inter-ramp instabilities depends on the amount of ramp loss and the overall volume of material in the failure. Priest and Brown suggest that failures in medium sized slopes of 50 to $100 \mathrm{~m}$ in height, with haulage roads or close to permanent mine installations may have serious consequences.

\subsubsection{Multivariate analysis techniques}

Multivariate analysis technique is used to create knowledge and thereby improve the decision making.
Multivariate analysis refers to all statistical techniques that simultaneously analyze multiple measurements on individuals or objects under investigation. An analysis, to be considered truly multivariate, all variables must be random and correlated in such way that the purpose of different effects cannot meaningfully be interpreted separately.

\subsubsection{Principal component analysis}

Principal component analysis is a multivariate statistical technique that uses an orthogonal transformation to convert a set of observations of correlated variables into uncorrelated variables named principal components.

The new variables (principal components) are linear combinations of the $p$ variables of the original data set. As Santos, T.B.D et al. 2019, there are six general equation in for both Principal component analysis and Discriminant analysis.

$\hat{Y}_{j}=\hat{e}_{j}^{t} X_{p x 1} j=1,2, \ldots, s \leqslant \min (k-1, p)$

Where PCi is the principal component $i, i=1,2 \ldots p ; e_{i}^{t}$ the transposed eigenvector $i$ of the correlation matrix of the data; and $\mathrm{X}$ the vector of original variables.

The variance of each principal component is equal to the eigenvalue related to the eigenvector of that component. Therefore, the proportion of total variance of the original data that is explained for the $\mathrm{i}^{\text {th }}$ principal component is calculated by Eq. (5)

$$
P_{i}=\frac{\lambda_{i}}{\sum_{i=1}^{p} \lambda_{i}}
$$

Where Pi is the proportion of total variance explained for the $\mathrm{i}^{\text {th }}$ principal component; and $\mathrm{p}$ the number of variables and $\lambda_{\mathrm{i}}$ the $\mathrm{i}^{\text {th }}$ eigenvalue.

Principal component analysis is a technique that is often used to quantify data with qualitative variables. Then, it is applied previously to techniques that can only be applied in quantitative data, e.g., discriminant analysis.

\subsubsection{Discriminant analysis}

Discriminant analysis is a multivariate technique used for classifying the elements of a sample in different populations. The technique must to be applied only in quantitative data. The classification rule is built using a function able to distinguish between two or more 
groups through original features that must be known for all the groups. Knowledge of the populations allows the formulation of a discrimination rule which can be used to classify new individuals. Fisher's canonical discriminant functions consist of linear combinations see Eq. (6)

$\hat{Y}_{j}=\hat{e}_{j}^{t} X_{p x 1} j=1,2, \ldots, s \leqslant \min (k-1, p)$

Where $\hat{e}_{j}$ is the $j^{\text {th }}$ eigenvector that corresponds to the $\mathrm{jth}$ greater eigenvalue of the matrix $\mathrm{W}-1 \mathrm{~B} ; \mathrm{X}$ the vector of variables; $\mathrm{W}$ the matrix of squares and cross products within the groups (Eq. (7)); and B the matrix of squares and cross products between groups (Eq. (8)). They are calculated as follows:

$$
W_{p x p}=\sum_{i=1}^{k} \sum_{b=1}^{n_{i}}\left(X_{i b}-X_{i}\right)\left(X_{i b}-X_{i}\right)^{t}
$$

$$
B_{p x p}=\sum_{i=1}^{k} \quad n_{i}\left(\bar{X}_{i}-\bar{X}\right)\left(\bar{X}_{i}-\bar{X}\right)^{t}
$$

Where $p$ is the number of variables; $k$ the number of populations; $n_{i}$ the number of elements in the class $i$; $X_{i b}$ the vector of observations of the sample element $b$ which belongs to population $\mathrm{i}$; $\mathrm{Xi}$ the vector of means for ith population; and $X$ the vector of means for the total sample. For each individual, a vector $Y_{j}$ is calculated. The scores of canonical discriminant functions applied to the vector of means for each class are also calculated $\left(\mathrm{Y}_{\mathrm{i}}\right)$. Then, the Euclidean distance between $\mathrm{Y} \mathrm{j}$ and $\mathrm{Yi}$ is calculated through Eq. (9). Finally, individuals are classified in the population whose Euclidean distance is smaller.

$$
d=\sqrt{\left(\hat{Y}_{j} \hat{Y}_{i}\right)^{t}\left(\hat{Y}_{j} \hat{Y}_{i}\right)}
$$

Fisher's canonical discriminant functions do not depend intrinsically on the multivariate normality of the data.

\section{RESULT AND DISCUSSION}

During Probabilistic assessment of rock slopes stability using the response surface approach the different data will be analyzed and finally modeled particular area from the large open pit mines by using different software like FLAC3D. That model tells us the in-situ stress, the rock strength, rock density, bulk modules, sheer modules, friction, cohesion and tensile strength

of

the specified area. The mechanical properties of the rock mass are estimated from the Hoek Brown classification investigation for the rock slope site. The results of this investigation have shown that the rock strength is good or poor rock as obtained from the point load test, the density of the rock sample is also analyzed, the rock slope surface condition is described as very blocky and the surface quality is described as poor to very good via fair, the geological strength index (GSI) for the rock mass is estimated to be in number but also in quantity. In addition, the disturbance factor has been taken as 1 for poor blasting and the effect of slope height has also been considered in the calculation of the rock mass properties, where the height used minimum of $20 \mathrm{~m}$.

When all numerical modeling simulations for rock slope realizations needed for BBD are completed and their corresponding responses (SRF) are obtained, the treatment combinations for all levels of random variables along with their responses are performed to establish the functional relationship between the independent variables and the response.

Through the BBD analysis, the main effects of all random variables, their interactions and their contributions on the variability of the obtained response are determined using a statistical technique called the Analysis of variance (ANOVA). This technique detects the differences between the levels of the random variables and measures the amount of deviation of the response, resulted from each treatment combination in the analysis, from the overall mean of the

responses. In other words, the Analysis of Variance is used in this study to identify the considerable (or most influential) random variables that impact the response (i.e. SRF). Each treatment combination between different levels of parameters in BBD is called an observation.

During Quantitative hazard assessment system (HasQ) for open pit mine slopes, depending on the technique used, it is possible to know the error associated with the obtained results which increases the confidence of engineers making decisions. Multivariate statistical techniques have been proven to be efficient for quantification of phenomena in many research fields as they provide quantitative methods of evaluation, in this case of the slope hazards. Principal component analysis was used to quantify the data from the database of different slopes. Discriminant analysis was carried out and a discriminant rule obtained with an error rate of $11.36 \%$. As the geotechnical parameters are inherently 


\section{International Journal of Engineering Applied Sciences and Technology, 2019 Vol. 4, Issue 8, ISSN No. 2455-2143, Pages 229-237 \\ Published Online December 2019 in IJEAST (http://www.ijeast.com)}

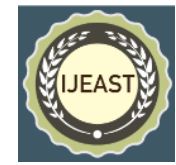

variable due to uncertainties in rock masses and the variability of the survey data of the other parameters, the error rate of the discriminant rule was considered reliable. Confidence ellipses were used to develop HAS-q which can be used to assess the hazards in mine slopes. HAS-q is a user-friend, powerful tool for hazard assessment as it provides an unbiased assessment of the hazards. Since it was developed based on different slopes data, from copper, gold, iron, diamond, lead and zinc, platinum and clay stone mines located around the world, with high variability in their geotechnical parameters, the HASq methodology can be used for all open pit slopes. As this is an empirical tool, future research can improve the database used to develop the HAS-q and to revise the transition zones between different hazard classes.

Principal component analysis was used to quantify the data. It is a prerequisite to apply discriminant analysis when the database has some qualitative variables. As the original data has parameters, these parameters were generated principal components.

Discriminant analysis the classification rule was built for three populations (statuses: stable (ST), inter-ramp and bench failures (FSB) and overall failures (OF)) using Fisher's canonical discriminant functions. These discriminant functions are normally used for homoscedastic data, i.e., data with the same population covariance matrices. Nevertheless, when the multivariate normality hypothesis cannot be assumed, Fisher's canonical discriminant functions are the preferred option, since quadratic discriminant analysis presents sensitivity to normality. Box's M Test was used to test the homoscedasticity population covariance matrix. Box's M test and multivariate normality test was carried out and the results are presented as a table or a chart form. As the p-value of Box's M test is smaller than 0.05, it is assumed that the data is not homoscedastic, making quadratic discriminant analysis an alternative. However, the p-value of the normality test approaches zero and, therefore, the multivariate normality hypothesis cannot be assumed. As quadratic discriminant analysis requires normality, Fisher's canonical discriminant functions were used. As the database has three populations, the classification rule has two discriminant functions.

\section{CONCLUSION}

As this paper mentioned there are a lot of slope stability assessment techniques but I am locking these best two methods. Both of them have their own critical advantage and basically using in different area of rock type. Probabilistic assessment of rock slopes stability determined for the dry and the saturated slopes while Quantitative hazard assessment system (Has-Q) is used for specifically for good rook like the geologic structure is not sophisticated but it is also valid for intermediate rock. But the error rate should be minimized.

\section{REFERENCE}

1. Brideau MA, Chauvin S, Andrieux P, Stead D. Influence of 3D statistical discontinuity variability on slope stability conditions. In: Landslides and engineered slopes: Protecting Society through improved understanding, Banff. p. 587-93

2. Call, R.D. and J.P. Savely (1990): Open Pit Rock Mechanics. Surface Mining, 2nd edition. Society for Mining, Metallurgy and Exploration, Inc., pp. 860-882. B.A. Kennedy ed.

3. Deere DU, Hendron AJ, Patton FD, Cording EJ. Design of surface and near surface construction in rock. In: Proceedings of the 8th U.S. Symposium on Rock Mechanics Failure and Breakage of Rock. New York: American Institute of Mining, Metallurgical and Petroleum Engineers, Inc.; 1967. p. $237 \mathrm{e} 302$.

4. Hammah, R.E., Yacoub, T.E., and Curran, J.H. 2008. Probabilistic slope analysis with the finite element method. In American Rock Mechanics Association (ARMA) 09-149.

5. Hoek E, Brown ET (1988) The Hoek-Brown failure criterion - a 1988 update. In: Curran J (ed) Proceedings of the 15th Canadian Rock Mechanics Symposium. University of Toronto, Toronto, pp 31-38.

6. Hoek E, Carranza-Torres CT, Corkum B (2002) Hoek-Brown failure criterion-2002 edition. In: Hammah R, Bawden W, Curran J, Telesnicki M (eds) Proceedings of the Fifth North American Rock Mechanics Symposium (NARMS-TAC), University of Toronto Press, Toronto, pp 267-273.

7. Hoek, E., Kaiser, P.K., and Bawden, W.F. 1995. Support of underground excavations in hard rock. A.A. Balkema, Rotterdam, p. 215

8. Kliche, C. (1999): Rock Slope Stability. Society for Mining, Metallurgy and Explorations, Inc., pp. 252.

9. M. Romana New adjustment ratings for application of Bieniawski classification to 
slopes. In: proceedings of international symposium on the role of rock mechanics ISRM, Zacatecas (1985), pp. 49-53.

10. O'Connor, K.M. and Wade, L.V. (1994), "Applications of Time Domain Reflectometry in the Mining Industry," Proceedings of the Symposium and Workshop on TDR in Environmental, Infrastructure and Mining Applications, Northwestern University, Evanston, IL, USA, September, pp. 494-506.

11. Sjöberg, J. (1996): Large Scale Slope Stability in Open Pit Mining - A Review. Technical Report 1996:10T, Division of Rock Mechanics, Lulea University of Technology, Sweden.

12. Santos, T.B.D., Lana, M.S., Pereira, T.M., Canbulat, I. Hide details Quantitative hazard assessment system (Has-Q) for open pit mine slopes. International Journal of Mining Science and Technology, Volume 29, Issue 3, May 2019

13. International Journal of Mining Science and Technology, Volume 29, Issue 3, May 2019 Stille, H., T. Groth and A. Fredriksson, 1982. FEM analysis of rack mechanics problems with JOBFEM. BeFo Swedish Rock Eng. Res. Found., 307: 82.

14. Szwedzicki, T., (ed.) (1993): Geotechnical Instrumentation and Monitoring in Open Pit and Underground Mining - Proceedings of the Australian Conference, Kalgoorlie. A.A. Balkema. 523 pp. 